\title{
JUSTIFICAÇÃO JURÍDICA DA RESPONSABILIDADE SOCIOAMBIENTAL EMPRESARIAL: RACIONALIDADE AMBIENTAL DAS REGRAS PRAGMÁTICAS À TOMADA DE DECISÃO
}

\section{ELISEU RAPHAEL VENTURI}

Doutorando em Direitos Humanos e Democracia pela Universidade Federal do Paraná (2015-2019). Mestre em Direitos Humanos e Democracia pela Universidade Federal do Paraná (2012-2014). Especialista em Direito Público pela Escola da Magistratura Federal no Paraná (2012). Graduado em Direito pelo Centro Universitário Curitiba (2010). Membro do Comitê de Ética em Pesquisa com Seres Humanos da Universidade Federal do Paraná. Advogado. eliseurventuri@gmail.com

\section{RESUMO}

O tema deste resumo expandido é o da Responsabilidade Socioambiental Empresarial. A delimitação do tema se dá na apreensão do tema no âmbito da Teoria da Argumentação, pela via da necessidade de justificação jurídica da tomada de decisão no contexto dos marcos regulatórios do tema.

O objetivo geral da pesquisa é o de apresentar um enfoque específico da questão da responsabilidade socioambiental empresarial que não 0 da regulamentação jurídica estrita de forma direta, mas sim a partir da mediação desta pelos potenciais interpretativos e argumentativos proporcionados pelas construções viáveis pela Teoria da Argumentação.

Como objetivos específicos adotam-se: a. identificar o marco regulatório básico da responsabilidade socioambiental no âmbito do ordenamento jurídico brasileiro; b. localizar, no contexto da Teoria da Argumentação Jurídica, os elementos propícios à análise e ao debate da responsabilidade socioambiental empresarial e seus desafios contemporâneos; c. mediar a interpretação e 


\section{Personalidade Acadêmica Homenageada:}

Florisbal de Souza Del'Olmo (Professor Convidado - UNICURITIBA)

argumentação da responsabilidade socioambiental com a problematização da justificação dos julgamentos de valor e de obrigação envoltos nesta responsabilidade jurídica específica, que envolve dimensões constitucionais, administrativas, penais, civis, ambientais e também éticas e morais.

O problema da pesquisa consiste em qual o espaço argumentativo em que se inserem as valorações jurídicas respectivas à responsabilidade socioambiental empresarial em termos de uma fundamentação das justificações dos processos de decisão respectivos à gestão socioambiental?

A hipótese central é a de que nas condições do processo de justificação das decisões encontra-se o espaço argumentativo necessário para a reflexão sobre os pressupostos de deontologia decisória que, por sua vez, refletem o potencial de realização dos preceitos jurídicos por meio do encaminhamento das condições limitadoras da percepção e da atuação sobre os problemas específicos de responsabilidade socioambiental empresarial.

A justificativa se faz, primeiro, por força da relevância contemporânea do tema da responsabilidade socioambiental empresarial, tanto no campo empírico, por meio das situações de riscos socioambientais vividos nas sociedades contemporâneas, quanto respectivamente à urgência e emergência do pensamento socioambiental por meio da racionalidade jurídica e suas formas de atuação institucional.

Como marco teórico adotam-se aportes: 1 . Sobre a justificação jurídica no campo da Teoria da Argumentação; 2. Sobre a responsabilidade socioambiental.

Respectivamente à justificação jurídica no campo da Teoria da Argumentação, importante momento de realização da razoabilidade (AARNIO, 1991) no desenvolvimento da produção hermenêutica e argumentativa contemporânea (FARALLI, 2006) (TROPER, 2008) da Filosofia Contemporânea do Direito, pode-se destacar a posição analisada pelo jurista alemão Robert Alexy (2001).

Nesta teoria, entende-se a justificação das razões das afirmações normativas e enfocam-se seus antecedentes lógicos de razões, motivos e regras, em sentido similar ao admitido em outros aportes de discussão, que realizam o mesmo movimento de análise linguística precedente à enunciação e à construção 


\section{Personalidade Acadêmica Homenageada:}

Florisbal de Souza Del'Olmo (Professor Convidado - UNICURITIBA)

dos discursos (ATIENZA, 2003, 2013) (GUASTINI, 2014) (MACCORMICK, 2006) (MORESO, 2006) (PERELMAN; OLBRECHTS-TYTECA, 2005). A tomada de decisões e eventual justificação expressa de seus motivos na dinâmica de comunicação são, assim, focos de análise e de construção metodológica e normativa.

Neste campo e recorte, toda decisão (seja judicial, administrativa ou mesmo dos cidadãos) na esfera pública comunicativa é, intencionalmente ou não, precedida de um processo de justificação que revela conteúdos discursivos envolvidos no contexto e no corpo da produção decisório. Este, ao seu turno, é regido por regras pragmáticas de racionalidade. Tais regras pragmáticas, no cerne das quais se pode também pensar e propor a presença da racionalidade ambiental (LEFF, 2001, 2006a, 2006b), realizam critérios de construção do discurso que, sendo jurídico, encontra-se limitado por estatutos, precedentes, dogmática jurídica, valores e demais fontes. As condições que orientam o processo de justificação, assim, influenciam diretamente o caminho da tomada de decisão na medida em que determinam escolhas, conferem rumos, geram preferências e encadeiam valorações e interpretações.

A partir deste quadrante da Teoria da Argumentação, pode-se visualizar a responsabilidade empresarial socioambiental (MILARÉ, 2011) como prática de prudência, prevenção e precaução de danos a direitos socioambientais, orientada tanto por marcos jurídicos (CAMPOS; ARDISSON, 2012) quanto por verdadeiros desenhos institucionais que estruturam as iniciativas socioambientais (KELM; RENZ; ALLEBRANDT; SAUSEN, 2014). Nesse sentido, sua série de preceitos ecossocioeconômicos (SACHS, 2007), operantes segundo uma noção de desenvolvimento includente, sustentável e sustentado (SACHS, 2004), assim como por pautas e instrumentos de gestão da responsabilidade socioambiental (LOUETTE, 2007, 2009) são presentes na promoção e proteção de direitos subjetivos, perfazendo o sentido jurídico propriamente dito em termos de direitos, deveres e responsabilidades.

Quanto à metodologia, trata-se de pesquisa teórico-acadêmica e qualitativa, sendo em seus objetivos descritivo-explicativa e, nos procedimentos 


\section{Personalidade Acadêmica Homenageada:}

Florisbal de Souza Del'Olmo (Professor Convidado - UNICURITIBA)

técnicos, bibliográfica, com base lógica em raciocínio dialético e especulativo. $\mathrm{O}$ campo de reflexão e o da inter-relação entre Direito Empresarial, Direito Constitucional, Direito Internacional dos Direitos Humanos e Direito Socioambiental, com recorte temático da Teoria da Argumentação.

Enquanto resultados e contribuições deste estudo, destacam-se: 1. Um modo, metodologicamente preocupado e orientado, de compreensão da construção das justificações no orbe da vigência e da realização da responsabilidade socioambiental, por meio dos processos argumentativos envolvidos nas interpretações e valorações realizadas em situações-problema que envolvam tal demanda analítica; 2. Um critério complementar aos critérios mesmos de racionalidade comunicacional das teorias da argumentação, integrando-se, por meio da racionalidade ambiental, uma dimensão a mais no universo de possíveis razões jurídicas, inclusive no tocante à avaliação da qualidade das razões oferecidas e da validade ou invalidade dos argumentos expostos. É no campo dos argumentos justificativos que adotem tal dimensão de racionalidade que se dará a maior contribuição do debate, em uma estrutura decisiva à construção normativa envolvida nos processos decisórios.

Uma importante consideração final sobre a contribuição do estudo diz respeito, novamente, à superação da tendência instrumental que pode reduzir a racionalidade econômica (LEFF, 2001, 2006a, 2006b), gerando profundas distorções jurídicas, sobretudo, nas expectativas do desenvolvimento integral e sustentável, expresso com força na figura da responsabilidade socioambiental empresarial. Nesse sentido, reitera-se que a presença da racionalidade ambiental, no cerne dos processos de justificação, pode vir a ser decisivo e consonante aos preceitos do ordenamento jurídico da tutela socioambiental.

\section{REFERÊNCIAS}

AARNIO, Aulis. Lo racional como razonable. Un tratado sobre la justificación jurídica. Madrid: Centro de Estudios Constitucionales, 1991. 
Personalidade Acadêmica Homenageada:

Florisbal de Souza Del'OImo (Professor Convidado - UNICURITIBA)

ALEXY, Robert. Teoria da argumentação jurídica. Tradução de Zilda Hutchinson Schild Silva. São Paulo: Landy, 2001.

ATIENZA, Manuel. As razões do direito. Teorias da argumentação jurídica. Tradução de Maria Cristina Guimarães Cupertino. São Paulo: Landy, 2003.

ATIENZA, Manuel. Curso de argumentación jurídica. Madrid: Trotta, 2013.

CAMPOS, Adrian; ARDISSON, Daniel Piovanelli. Por uma nova concepção jurídica de empresa no marco da sociedade do risco: do lucro inconsequente à responsabilidade socioambiental. Sequência, Florianópolis, n. 64, p. 85-104, 2012.

FARALLI, Carla. A filosofia contemporânea do Direito. Tradução de Candice Preamor Gullo. São Paulo: Martins Fontes, 2006.

GUASTINI, Riccardo. Interpretar $\boldsymbol{y}$ argumentar. Tradução de Silvina Álvarez Medina. Madrid: Centro de Estudios Políticos y Constitucionales, 2014.

KELM, Martinho Luis; RENZ, Cíntia Lisiane da Silva; ALLEBRANDT, Sérgio Luís; SAUSEN, Jorge Oneide. Institucionalização das iniciativas socioambientais das organizações: interfaces entre a teoria do desenvolvimento social de Habermas e o isomorfismo da teoria institucional. Cadernos EBAPE.BR, online, v.12, n.spe., p.401-415, 2014.

LEFF, Enrique. Epistemologia ambiental. 4. ed. São Paulo: Cortez, 2006b.

- Racionalidade ambiental: a reapropriação social da natureza. Rio de Janeiro: Civilização Brasileira, 2006a.

Saber Ambiental: sustentabilidade, racionalidade, complexidade, poder. Petrópolis/RJ: Vozes, 2001.

LOUETTE, Anne (Org.). Compêndio de indicadores de sustentabilidade das nações. São Paulo: Antakarana Cultura Arte Ciência/Willis Harman House, 2009.

. Compêndio para a sustentabilidade. Ferramentas de Gestão de Responsabilidade Socioambiental. São Paulo: Instituto AntaKarana, 2007.

MACCORMICK, Neil. Argumentação jurídica e teoria do direito. Tradução de Waldéa Barcellos. São Paulo: Martins Fontes, 2006.

MILARÉ, Édis. Direito do ambiente: a gestão ambiental em foco. 7. ed. São Paulo: Revista dos tribunais, 2011.

MORESO, Josep Joan. Lógica, argumentación e interpretación en el derecho. Barcelona: UOC, 2006. 
Personalidade Acadêmica Homenageada:

Florisbal de Souza Del'OImo (Professor Convidado - UNICURITIBA)

PERELMAN, Chaim; OLBRECHTS-TYTECA, Lucie. Tratado da argumentação. A nova retórica. Tradução de Maria Ermantina de Almeida Prado Galvão. São Paulo: Martins Fontes, 2005.

SACHS, Ignacy. Desenvolvimento includente, sustentável, sustentado. Rio de Janeiro: Garamond, 2004.

Rumo à ecossocioeconomia: teoria e prática do desenvolvimento. São Paulo: Cortez, 2007.

TROPER, Michel. A filosofia do direito. Tradução de Ana Deiró. São Paulo: Martins Fontes, 2008. 